\title{
Study on the Transformation from Information Services to Knowledge Services
}

\author{
Dake Wang \\ Library of Primary Flight Training Base \\ Aviation University of Air Force \\ Changchun, China 130062
}

\author{
Lili Zhao \\ Library of Primary Flight Training Base \\ Aviation University of Air Force \\ Changchun, China 130062
}

\author{
Lishu Zhang \\ Library of Primary Flight Training Base \\ Aviation University of Air Force \\ Changchun, China 130062
}

\begin{abstract}
The article elaborates the connection and difference between information services and knowledge services, the inevitability of the transformation of information services into knowledge services and the characteristics of knowledge services. It also discusses the deep impact of modern information environment and knowledge services on the library, analyzes the disparity of information services and the connotation of knowledge services, and points out that knowledge services are fundamental to libraries.
\end{abstract}

Keywords-information services; knowledge services; service mode

\section{INTRODUCTION}

The Development Outline of Libraries of military institute libraries clearly points out that military institutes should adhere to the library digitization construction, adopt a policy of optimizing structure, enhancing functions, positive adaptation, and active service, taking the path of overall development, profitable development, and characteristic development to improve guarantee capabilities of information services. The Construction of Chinese army library resources develops exceptionally fast, which opens up a vast world for user services. However, in the process of library services, there is indeed a gap between subjective cognition and objective reality. There are also many problems in the dominant thinking and actual development and utilization, which hinder the construction of resources and the quality of user services.

The construction of the military training information network offers a most effective platform for users to make full use of various digital resources, making information retrieval and acquisition more convenient, simpler, and faster. Distance is no longer an obstacle, and the focus of user demand has shifted to the choice of information content. That is, the value orientation of libraries has shifted to "knowledge services" today. It spurs us to explore the nature of information services and knowledge services, find out new knowledge service models, and establish a service system with greater capabilities and vitality, so as to expand, deepen and sublimate library services.

\section{THE CONNECTION BETWEEN KNOWLEDGE SERVICES AND INFORMATION SERVICES}

Knowledge services are to develop and process useful knowledge resources from a large number of document resources by adopting a variety of approaches and methods, including the knowledge and experience that can be communicated and shared, the information they organize and so on. It enhances the visibility of knowledge for users to absorb, use, and derive inspiration through orderly disclosure of things themselves and their internal connections. Knowledge services create harmonious knowledge ecology through knowledge management, and they rely on internal innovation to adapt to the environment in order to develop the subject. However, information services are response measures to meet specific information needs.

Both of them attach great importance to information and information technology. In the era of knowledge economy, both of them use information as basic raw materials, use information technology to establish an effective knowledge management and service system, and transfer relevant contents from people who knows to the ones who do not know. Information and information technology are not only used by information services, but also provide knowledge services with solutions and methods.

The two promote and develop each other. Knowledge services are based on information services and impose higher requirements on them, because every service and decision cannot be separated from information. Knowledge services are no exception, and they have higher requirements for the comprehensiveness, accuracy, and timeliness of information. Good information services are the basis for realizing knowledge service, and the progress of knowledge service research will inevitably drive the development of information services. 
Information services are responses to meet the needs of specific information, and that's why they achieve the purpose through information giving. However, knowledge services ultimately creating harmonious knowledge ecology are through knowledge management forming "self-sufficient" innovations or relying on an internal constant innovation mechanism to adapt to the environment and develop the subject. The problems they focus on are different, but the effects are basically the same.

Information is the raw material and source of knowledge innovation. Knowledge does not generate in people's minds out of the void. When studying the law of knowledge movement, it is necessary to conduct in-depth discussions on information. This is determined by the inherent relationship between knowledge and information. In the era of knowledge economy based on computer and communication technology, information technology has become an important tool for knowledge service. Knowledge services establish effective knowledge management and service system by the use of information technology, so that knowledge transfers from people who know to the ones who do not know. It can be seen that information technology is not only used by information service, but provides knowledge services with methods and means to solve problems. Therefore, both of them should be attached great importance to.

From the above points, it can be seen that knowledge services are the growing points of information resources in the new century and are effective ways to develop knowledge economy and improve the level of knowledge innovation. With the advent of the knowledge economy in the new century, it has become inevitable that information services transform into knowledge services.

\section{THE DIFFERENCE BETWEEN KNOWLEDGE SERVICES AND INFORMATION SERVICES}

Analyzing from the differences of connotation, the main differences between the two lie in:

- Knowledge services are the services driven by users. The focus and final evaluation of them are not only providing users with the information they need, but also solving problems that users faced through services. The basic, key and terminal points of traditional information services are the acquisition and transmission of information resources.

- Knowledge services are content-oriented services. They attach great importance to user issues and problem environments, and conduct systematic analysis based on them through the absorption and reorganization of information to form a knowledge product that is easy to understand and use in line with the needs of users, and at the same time evaluate the quality of knowledge products. Traditional information services are based on users' simple questions and services based on literature physics.

- Knowledge services are solution-oriented services and run through the entire process of solving problems. It is concerned and committed to helping users find or form solutions to problems. According to the users' requirements, the information and knowledge are continuously queried, analyzed and organized to serve users dynamically and continuously. However, traditional information services rest content with the provision of specific information, data or documents.

- Knowledge services are value-added services. It is not limited to provide users with information storage location and access in order, but focuses and emphasizes on processing ready-made documents by the use of their unique knowledge and ability to form new information products with unique values, solve problems that cannot be solved by users and improve the efficiency of users' knowledge applications and knowledge innovation.

- Knowledge services are user-driven services. The basic points, priorities, end points, and core capabilities of traditional information services are the acquisition, organization, retrieval, and transmission of information resources. It contains little effective knowledge. It is difficult to adapt to the needs of knowledge economy development and knowledge innovation, and cannot blend in the core process of users' knowledge applications and innovations effectively. However, the focus and final evaluation of knowledge services is not only to provide users with the required information, but to solve the problems that users face through service. That's why knowledge services can meet the needs that cannot be met by information services.

\section{THE NECESSITY OF INFORMATION SERVICES TRANSFORMING TO KNOWLEDGE SERVICES}

Knowledge services are to meet the needs of the development of knowledge economy and the innovation of knowledge innovation with the goal of solving users' problems. It provides users with intellectualized knowledge products tailored for users' needs through analysis on the needs of user knowledge and the problem environment.

Knowledge economy has an impact on information services. Traditional information services are facing a serious impact of knowledge economy. The distinguishing features of knowledge economy are that knowledge is a key element of productivity, and products and services are increasingly informative and knowledgeable. The value and competitiveness of products and services are mainly reflected in their knowledge content rather than the quantity of information resources. Traditional information services have few effective knowledge contents, and it is difficult to adapt to the needs of knowledge economy development and knowledge innovation. Its core competences are positioned in knowledge services, that is, the core capabilities of knowledge services are formed through the absorption, arrangement, integration, and innovation of knowledge information, and integrating the core capability into the 
solution of user issues and environmental analysis to provide services that can effectively support knowledge innovation.

Modern information environment is challenging for information services. In the modern information environment, the uneven distribution of information resources and the information acquisition environment have been improved greatly, and the impact of traditional information services on user activities has gradually diminished. The focuses of users are how to capture and extract knowledge contents that can solve practical problems, and innovate and integrate them to transform into corresponding solutions. Therefore, it is needed to directly integrate into the entire process of solving problems, and help users solve problems more directly based on specific problems and personalized environment. Obviously, information service with information retrieval and transmission as the core is difficult to do this. What takes the place of knowledge services necessarily is the inheritance of information service essence.

The basic ability of libraries is to have abundant documentary information resources and provides traditional circulation services and information services. With the socialization and networking of the information environment, what information units are faced with are the continuous decline in the physical growth of document resources, and their original basic service functions can no longer meet the needs of the society. What users are concerned about is not simply to obtain documents, but how to capture and extract useful information from the complicated ones, and integrate and reorganize the information into the core knowledge content that can solve problems. Therefore, the needs of users are those can integrate into the entire process of solving problems and help them solve problems directly based on specific issues and individual environments - that is what we call knowledge services.

Modern society requires the refinement of knowledge services. Users are no longer satisfied with being offered with general knowledge services. Instead, what they need are core knowledge contents for solving problem. It requires the integration of professional knowledge scattered in the field and related fields, and extracting the "knowledge products" useful for users' researches, development and innovation from it.

\section{Features of KNOWLEDGe SERVICES}

Social needs requires that strengthening service functions, providing services that can be integrated into problemsolving processes and aimed at specific problems and personalized environments more directly, and help them solve problems more directly, namely, knowledge service.

The advantages of knowledge services are reflected in the following aspects. Knowledge management includes all activities implemented by libraries and intelligence departments to realize the effective support of knowledge to the core business. The goal is to improve the innovative service capabilities of libraries and intelligence department through the use of collective wisdom. Its characteristics include: first, discovering new knowledge points and relations between knowledge in the complex information flow, organizing them into the database in accordance with the knowledge system, and then making it easy for people to retrieve relevant data and knowledge through computer technology and network technology starting from the goals and environment of users and the use of information technology and database technology; second, Consultants can communicate with each other and users through the database and computer intranet, etc., thereby organically linking information with information, information with people, and information with processes to match and transfer information more timely and accurately; third, utilizing the knowledge analysis and application functions of the expert system and decision support system to establish and develop various management mechanisms to stimulate knowledge service personnel to participate in knowledge sharing and knowledge innovation actively.

Knowledge services are the services that integrate into users and permeate users' decision-making process, rather than services that are based on information institutions and far from users. It requires more clear and close contact between service personnel and users.

Knowledge services are the services based on professionalization and individualization. Professionalization requires organizing and implementing services according to specific fields or subject areas. Personnel providing services should have expertise in this area to ensure the grasp of users' issues and their environment aiming at improving the quality of knowledge services. Personalization requires providing services specific to the needs of specific users. It requires service personnel to understand, track and maintain users' demand and provide comprehensive information services.

Knowledge services are the services based on distributed and diversified dynamic resources and system, and they are not the services based on inherent resources or systems. It is a kind of virtualized service that fully mobilizes and integrates various resources, systems, and services to support the functions and processes of knowledge services.

Knowledge services are the service based on integration. They combine and coordinate through open service models, system integration, service integration, and team integration, and organize and provide knowledge services by the use of a variety of knowledge, resources, people, systems, and services.

Knowledge services are the services based on independence and innovation. Each knowledge service must collect, select, analyze, and utilize various knowledge creatively and dynamically based on actual needs. It should design, organize, arrange, and coordinate related service work creatively. Furthermore, the capabilities of creative research, management, and service as well as the establishment of corresponding management mechanism of knowledge service are also needed.

The inevitability of information services transforming to knowledge services. The influence of traditional information services on user activities gradually diminished. What users are more concerned with are how to capture and acquire 
knowledge contents that can solve their actual problems, and innovate and solidify these knowledge contents to be in new products. Therefore, it is necessary to directly integrate the services into the entire process of users to solve their problems, and help them solve problems more directly by addressing the specific problems and the personalized environment. Obviously, centering on information retrieval and transmission, information services are difficult to achieve the purpose, and they will be definitely replaced by knowledge services deepening information services.

Modern society requires the refinement of knowledge services. Users are no longer satisfied with being offered with general knowledge services. Instead, what they need are core knowledge contents for solving problem. It requires the integration of related professional knowledge and extracts well-targeted knowledge of high-quality. For this purpose, knowledge service personnel not only need to understand the process of problem-solving, but analyze users' demand experience and integrate it into the users and their decisionmaking process, run through the process of problem-solving, establish a responsibility system of service record for the specific user system and the entire process, and offer integrated services from knowledge capture, extraction, reorganization, innovation, integration to application.

The Joint Committee of All-Army Libraries proposes a thought of information resource construction based on "integrated layout, division of labor and collaboration, joint research, and joint construction and sharing", in an effort to give full play to the overall advantages of all collaborating units and form a joint security model of dynamically developing resource system with the core of user service. Under the guidance of the general idea, the necessary organization and disclosure of knowledge information resources will form a new environment for the development and utilization of knowledge resources.

\section{KNOWLEDGE SERVICES ARE THE FOUNDATIONS OF LIBRARIES}

The development direction of libraries is digital library, and the ultimate goal of digital libraries is knowledge of information offer. Various types of information resources are organically combined on the basis of knowledge units to provide services for users in a dynamic and distributed manner. Digital technologies, knowledge discovery and organizational technology such as the interconnection of automatic indexing, metadata, content retrieval, and different databases become key technologies.

Services are the eternal themes of libraries. The status and roles of the libraries will depend on whether they can provide users with continuous, complete, and systematic knowledge and the quantity and quality of knowledge as required. In this process, the libraries should deepen and enrich information as well as provide diversified services by using various methods, means, and technologies according to the needs of users. The shallow services in the past have turned to deep-level changes of providing documentation units, information units, facts and data, dynamic information, and reviewing information and so on. The original carriers providing has turned to a comprehensive service pattern based on special subjects and knowledge units.

The rapid development of the network exceeds our expectation. The network needs content; content drives services, and services further stimulate the operation law of network and content. The advancement of network technology has brought about a qualitative leap in information expression and transmission. The network has provided the most powerful technical support for the sharing of information resources. The military training information network is one of the most practical and effective ways and methods for developing and securing information resources systems. It provides a huge space of knowledge services including knowledge transfer, knowledge exchange, network navigation, and push services for comprehensive knowledge service forms. The original state of lacking coordination formed joint development, common construction, and common use through the Internet, and knowledge services eventually became the core and foundation of the joint security system.

The libraries of Chinese military advocate "all libraries in the military share common information". However, the actual information resources construction is still fiercely independent. Information on the Internet is not inherently allencompassing. The missing may be exactly what is needed, and what exists may not be what is seeking. It like looking for a needle in a haystack to inquire about valuable content, and it is impossible to find rigorous and scientific system knowledge. Only built on the basis of resources integration, targeting providing users with knowledge services and having a variety of search channels and online platforms are the real digital libraries.

\section{CONCLUSION}

Modern libraries should adapt to changes in the information technology environment, break the backward organizational structure and service model, and carry out deep-level reforms from ideas and concepts to technical methods so as to adapt to the transformation from information services to knowledge services. What it provides is the concept of system integration together with innovating various functions of libraries and playing the roles of "knowledge warehouse", "launching tower of knowledge" and "knowledge fountain", to acquire and accumulate knowledge, supplement and update knowledge, carry out the process of "eliminating the false and retaining the true" as well as "discarding the dross and keeping the finer part" and carry out creative thinking.

\section{REFERENCES}

[1] Qiu Junping and others. Talking on Knowledge Management and Information Management. Library and Information Service, 2000.10. 邱均平等. 论知识管理与信息管理. 图书情报工作, 2000.10

[2] Zheng Lixian. Positioning and Development of Library in the Transition Period. Newsletter of Library and Information Service, 2002.5. 郑丽仙. 图书馆转型时期的定位与走向. 图书馆情报工作动 态, 2002.5 
[3] Wu Xiaobo. Development and Positioning of Digital Libraries. The Journal of the Library Science in Jiangxi, 2003.1. 吴晓波. 数字图书 馆的发展与定位.江西图书馆学刊, 2003.1

[4] Dai Weimin. Ten Relations in the Development of Digital Libraries. Journal of PLA University of Science and Technology, 2003.3. 戴维 民. 论数字图书馆发展中的十大关系.解放军理工大学学报, 2003.3

[5] Qi Fangyuan. The Transformation of Information Services to Knowledge Services. Inner Mongolia Science technology \& Economy, 2009.07. 齐方圆. 信息服务向知识服务转变.内蒙古科技 与经济, 2009.07

[6] Zhang Jinhuan. Development Trend and Knowledge Service of University Library Information Service under Network Environment. Library and Information Service, 2011.11. 张金环.网络环境下高校 图书馆信息服务发展趋势与知识服务. 图书情报工作杂志社, 2011.11 